\title{
Commentary on: "Hydrocephalus Following Bilateral Dumbbell-Shaped C2 Spinal Neurofibromas Resection and Postoperative Cervical Pseudomeningocele in a Patient with Neurofibromatosis Type 1: A Case Report"
}

\author{
Andrew T. Dailey ${ }^{1}$ \\ ${ }^{1}$ Department of Neurosurgery, University of Utah Health Care, \\ Salt Lake City, Utah, United States \\ Evid Based Spine Care J 2014;5:139-140.
}

Address for correspondence Andrew T. Dailey, MD, Department of Neurosurgery, University of Utah Health Care, Salt Lake City, UT 84132 , United States (e-mail: andrew.dailey@hsc.utah.edu).
In this report, Nicola and colleagues report the occurrence of hydrocephalus 1 month after resection of dumbbell C2 neurofibromas. Prior to surgical intervention, the patient had a mild progressive quadriparesis, which improved after tumor resection. At 1 month postoperatively, the patient had a pseudomeningocele and enlarging ventricles consistent with the symptomatic hydrocephalus.

Hydrocephalus can occur in patients with neurofibromatosis type 1 but is usually associated with optic pathway gliomas, thalamic and hypothalamic tumors, intrinsic brainstem gliomas, or aqueductal stenosis. ${ }^{1}$ Furthermore, hydrocephalus is a well-described entity with spinal cord tumors, and it is estimated that $1 \%$ of patients with spinal cord tumors present have hydrocephalus at presentation. ${ }^{2}$ Most commonly, hydrocephalus is associated with intrinsic spinal cord tumors (75\%), though it can happen with extramedullary tumors. Several mechanisms have been implicated, including increased protein from tumor or hemorrhage, obstruction of cerebrospinal fluid (CSF) pathways, or even neoplastic seeding. However, if it is identified before surgery, it is important to resect the spinal cord tumor before inserting a shunt to avoid shunt-related neurological deterioration. The authors of this report suggest that there was no hydrocephalus on presentation, though it is uncertain if this was evaluated radiologically.

The most likely etiology for the hydrocephalus is a postoperative pseudomeningocele or CSF fistula with compression of the foramina of Magendie and Luschka, preventing normal CSF flow. In large series of posterior fossa decompressions for etiologies such as Chiari malformations or tumors, CSF leaks and pseudomeningoceles can form at rates of 6 to $10 \%$ with delayed hydrocephalus presenting in 3 to $5 \%$

received

July 2, 2014

accepted

July 2, 2014 of patients. ${ }^{3,4}$ In children with posterior fossa tumors, the rate of postoperative hydrocephalus is very high, with $30 \%$ needing additional intervention after the original operation. ${ }^{5}$ The presence of a postoperative pseudomeningocele in these patients is a harbinger of hydrocephalus as it was in the current case. Hydrocephalus can also occur after closed head injury with estimates of posttraumatic hydrocephalus as high as $30 \%$ in patients with severe closed head injury. If the patient has concomitant injury to the upper cervical spine that requires intervention, a pseudomeningocele may form at the site of cervical injury with cranial imaging revealing ventricular enlargement. ${ }^{6,7}$ The mechanism of posttraumatic hydrocephalus formation is not dissimilar to the presumed mechanism in the current case with obstruction of CSF outflow from the cranium or decreased resorption of CSF due to blood and protein blocking the arachnoid granulations. In any event, the authors astutely recognized that this patient's pseudomeningocele was a sign of hydrocephalus and treated the hydrocephalus before further morbidity or even death ensued.

\section{References}

1 Binning MJ, Liu JK, Kestle JRW, Brockmeyer DL, Walker ML. Optic pathway gliomas: a review. Neurosurg Focus 2007;23(5):E2

2 Mirone G, Cinalli G, Spennato P, Ruggiero C, Aliberti F. Hydrocephalus and spinal cord tumors: a review. Childs Nerv Syst 2011; 27(10):1741-1749

3 Klekamp J. Surgical treatment of Chiari I malformation-analysis of intraoperative findings, complications, and outcome for 371 foramen magnum decompressions. Neurosurgery 2012;71(2):365-380, discussion 380 (c) 2014 Georg Thieme Verlag KG Stuttgart · New York
DOI http://dx.doi.org/ 10.1055/s-0034-1387802. ISSN 1663-7976. 
4 Dubey A, Sung WS, Shaya M, et al. Complications of posterior cranial fossa surgery-an institutional experience of 500 patients. Surg Neurol 2009;72(4):369-375

5 Riva-Cambrin J, Detsky AS, Lamberti-Pasculli M, et al. Predicting postresection hydrocephalus in pediatric patients with posterior fossa tumors. J Neurosurg Pediatr 2009;3(5):378-385
6 Pahys JM, Chicorelli AM, Asghar J, Betz RR, Samdani AF. Cervical pseudomeningocele due to occult hydrocephalus. Spine (Phila Pa 1976) 2008;33(12):E394-E396

7 Reed CM, Campbell SE, Beall DP, Bui JS, Stefko RM. Atlanto-occipital dislocation with traumatic pseudomeningocele formation and posttraumatic syringomyelia. Spine (Phila Pa 1976) 2005;30(5):E128-E133 